tide having the unoxpected range of about 1 mile, and producing by dynamo action a system of electric currents, detectable by their magnetic effects at the ground, apparently flowing in or below the $E$ layer.

There also flows in the ionosphere a system of currents wholly governed by the sun, manifesting themselves by ordinary daily magnetic variations, the total current being about 200,000 amp., roughly. ten times as great as those due to lunar tides. The total current intensity in the greater system is only about twice that of a single lightning flash and the current density is extremely low, contributing inappreciably to the heating of the atmosphere. In a quite moderate storm there appears to be an intense current system (more than half a million amperes) in the ionosphere over each polar cap; the magnetic effects over the remaining 90 per cent of the earth betoken a current system of about the same total intensity.

\section{ELECTRONICS IN INDUSTRY}

$\mathrm{I}^{\mathrm{N}}$ May 1941, as a result of considerable interest in the various branches of industrial radiology, the Institute of Physics formed an Industrial Radiology Group (see Nature, June 7, 1941, p. 706). Recently there has been a widely expressed wish among members of the Institute for the formation of a similar group for electronics. It was decided, therefore, to hold a Conference on Electronics to ascertain whether there existed sufficient interest to justify the formation of such a group. This Conference was held at the Royal Institution on January 28 under the presidency of Prof. J. D. Cockeroft. It consisted in the reading of three papers followed by a general discussion and was well attended, members from many parts of Great Britain being present, as is usual at such meetings of the Institute.

Prof. Cockcroft, opening the proceedings, spoke of the widening field of application of electronic devices, and said that it is becoming increasingly difficult for physicists to keep in touch with developments in such specialist fields. He thought that the Conference would justify itself if it helped to minimize this difficulty.

The first paper, on "The Efficient Production of Light by the Electric Discharge", was read by V. J. Francis of the General Electric Company. The author pointed out that the scientific study of the efficient conversion of energy into radiation by means of electric discharges in gases is comparatively recent. Although the efficiency obtainable is several times that possible by any other known means, in practical lamps the efficiency of conversion is still only $12-15$ per cent, and a wide field for research still exists. Under certain ideal experimental conditions, efficiencies as great as 90 per cent have been recorded.

Mr. Francis then discussed the sodium and mercury vapour discharges in order to explain some of the principles involved in obtaining high luminous efficiency. The former requires low pressure and low current density because the resonance radiation is in a useful part of the visible spectrum; while with mercury, where the useful transitions are between excited states, the conditions leading to high efficiency are high pressure and high current density. He then dealt briefly with some of the applications of luminescent powders to discharge lamps. In one interesting application, practically all the light is obtained from the luminescent powder, which is excited by ultra- violet radiation produced with an efficiency of some 70 per cent in the low-pressure mercury vapour discharge. Finally, the possibilities of the mercury vapour discharge as a high-brightness source were mentioned; very high brightnesses are possible by this mears.

The next paper, on "The Control Characteristics of Thyratrons and Ignitrons", was given by H. de B. Knight, of the British Thomson-Houston Company. The author first dealt with the dependence of the ratings and control characteristics of hot-cathode thyratrons on cathode emission, on the geometry of the electrodes and envelope, and on the gas or vapour density. In gas-filled valves the density is constant and control characteristics are independent of temperature ; but the working voltage is limited to about 500 volts. For high power, mercury vapour is used ; but the vapour pressure must be controlled, especially for heavy current densities and high voltages (above $15 \mathrm{kv}$.) Mr. Knight showed many interesting curves illustrating these characteristics. Ionization time comprises a delay period in which practically no current passes, followed by a shorter 'build-up' period in which the plasma becomes established. Both periods are relatively independent of vapour pressure, but are affected by the grid voltage and resistance, and especially by the shapes of the electrodes and the field distribution in the are space. De-ionization time is a function not only of valve design but also of the circuit.

In dealing with mercury pool rectifiers, controlled by cathode spot formation, the author said that the 'Ignitron' alone finds wide industrial application. The delay time between the igniter current and the main arc depends on the rate of rise of igniter current. A delay of less than one microsecond can be obtained; but up to 50 microseconds or more is satisfactory for most industrial uses.

A. J. Maddock, of Standard Telephones and Cables, read the third paper, on "Hot-cathode Gas-filled Triodes (Thyratrons) and their Applications in Research and Industry". The author described the various ways in which these devices may be used. An outline of the principles of the several basie circuits that can be employed in most applications was given, and these were illustrated by interesting demonstrations so that the properties of the various circuits and the effects resulting from the use thereof were readily apparent.

The circuits discussed included those for use on A.c. and D.c. supplies, and showed the range of control obtainable in the former case as the point at which the grid loses control in each positive halfcycle of the alternating anode voltage is varied; and in the latter case how a second thyratron or switch may be used to stop the flow of current through a thyratron already passing current by applying a negative impulse to the anode of the first thyratron. Extension of this leads to the inverter circuit which produces an A.C. output from a D.C. input.

Several grid circuits were illustrated suitable for use in covering such applications and control as timing, impulse, variable reactance, variable resistance (including use of photo-electric cells), variable phase, etc. Examples of the use of these devices ranged from circuits for high-speed counting of physical phenomena and the generation of current pulses of accurate time duration used in research to large industrial plants such as high-tension rectifiers developing $600 \mathrm{kw}$. at 14,500 volts, large variablespeed motors operating on an A.c. supply, and 
inverters with the possibility of transmission at high D.c. voltages, together with the realization of a virtual static D.C. 'transformer'.

A lively discussion ensued which ranged over a number of topics, and in particular many questions were asked concerning the behaviour and application of the gas-filled triodes. It was clear, as Prof. Cockcroft said in closing the discussion, that there was sufficient interest for the Conference to go on indefinitely, and the Conference passed a resolution requesting the Board of the Institute of Physics to sanction the formation of an Electronics Group.

\section{UTILIZATION OF INDIAN HOME- GROWN TIMBERS}

A

FOREST Bulletin, No. 92, Utilization (New Series), has been written by V. D. Limaya of the Forest Research Institute, Dehra Dun, on "The Testing of Packing Cases for Army Boots and suggested Improvements." (Govt. of India Press, New Delhi, 1941). Packing cases for army boots in India have usually been made of chir (Pinus longifolia) in the past. Owing to the large demand brought about by the War, other timbers for the purpose have come under review. The Ordnance Department suggested that semul (Bombax malabaricum) might answer equally well and would be more easily available as the species is not more or less confined to the outer hills of the Himalayan range. Since, however, it is a softish wood, doubts were expressed as to its suitability. Comparative tests of both timbers were therefore undertaken in the Timber Testing Section of the Institute. These tests showed that semul boxes were practically as strong as chir boxes and possessed in addition certain advantages. But the tests went further, and indicate how war-time emergencies sharpen the faculties. It was discovered that the original design could be greatly improved so as to produce a far stronger box by very small additions costing not more than two annas a box. Boxes so made were tested and found to be fifteen times stronger than those made according to the original design. The advantages to an army at war will be readily understandable. Two plates show the old box and its failure to stand certain stresses and the new one.

Bulletin No. 93, by the same author, is entitled "Indian Timbers for Tool Helves and Handles". When there has been a Forest Department in India for nearly eighty years and a Research Institute for well over thirty, it is difficult to account for the fact that up to quite recently very large quantities of hickory and ash handles were imported from America into India annually. In fact the big American manufacturers were doubtless correct in saying that "We 'handle' the World". Hickory only grows in the lower Mississippi valley and yet hickory tool handles and helves are to be found in use in practically every country in the world. Ash is also used to a very large extent for the lighter types of handles. These two species have very nearly monopolized the tool handle trade of the world. Until comparatively recently this remained true for India in spite of the large number of species growing in the great Indian forests.

The work carried out at the Forest Research Institute has, however, resulted in greater interest being taken in Indian timbers in this respect, with the result that more than three quarters of the railway demand for tool handles (the largest demand in the country) is now met by handles made in India from Indian woods.

The author states that "wooden handles for tools are really becoming a world problem". Manufacturing processes require the use of various types of cutting tools and hammers and the demand for wooden handles for such tools has increased enormously. While admitting that hickory is rather a special type of timber and that it will probably remain in demand for special uses, it is now proved that certain Indian timbers fulfil the requirements for tool handles. The research work of the Timber Testing Department had resulted in the markets being supplied with tool handles made from Indian timbers, and the War has given a great impetus to the tool handle trade, large orders having been placed for pick-axe helves, hammer handles, axe-helves, wooden mallets, handles for entrenching tools, spades and so forth.

Some of the species of timbers used belong to about twenty genera. These, according to their qualities, are used for heavy hammer handles (hickory class), light hammer handles (ash class), axe helves (hickory (lass), handles for scooping tools (ash class) and handles for cutting tools (beech class). Other woods of small forest species are being tested. For example, Anogeissus pendula, which until recently was practically unknown as a tool handle wood, has been found to be the toughest timber ever tested.

\section{DOWNWARD RADIATION OF THE EARTH'S ATMOSPHERE}

IN Scientific Notes of the India Meteorological Department (8, No. 93) R. Narayanaswami gives a comparison between measurements of the downward radiation of the earth's atmosphere at night made by himself at Bombay between March 1937 and October 1938 and similar observations by Ramanathan and Desai at Poona in $1930-31$. The interest of the comparison lies in the fact that the climates of the two places are in strong contrast, Bombay having a coastal climate of exceptional dampness, while at Poona the climate is continental apart from the rainy season (June-September), and at times very dry, the annual rainfalls being about $70 \mathrm{in}$. and $27 \mathrm{in}$. respectively.

The instrument used both at Bombay and at Poona for measuring the atmospheric radiation was Angstrom's pyrgeometer No. 48, made by G. Rose of Upsala. With this was measured the net radiation per horizontal square centimetre, that is, the difference between the full emitted black body radiation given by $\sigma T^{4}$ and the radiation received from the atmosphere, interest attaching mainly to the comparison between the ratio sky radiation to full radiation, and the vapour pressure of the air around the instrument calculated from the readings of an Assmann psychrometer. Since the radiation from the sky is practically all due to the water vapour in the atmosphere, dry air being an exceedingly bad radiator, in so far as there is considerable positive correlation between the water vapour pressure near the ground and in the overlying atmosphere as a whole, so the ratio $S / \sigma T^{1}$, where $S$ is the sky radia. tion, and the vapour pressure near the ground, show high positive correlation. Comparison between these quantities and the dry-bulb reading of the Assmann psychrometer is made by tables and graphs. 